\title{
ACHONDROPLASIA AND ELLIS VAN CREVELD SYNDROME
}

\author{
G. Ramkumar1, P. Shanmugasundaram², V. L. Narayanan ${ }^{3}$
}

\section{HOW TO CITE THIS ARTICLE:}

G. Ramkumar, P. Shanmugasundaram, V. L. Narayanan. "Achondroplasia and Ellis Van Creveld Syndrome". Journal of Evolution of Medical and Dental Sciences 2014; Vol. 3, Issue 12, March 24; Page: 3076-3080, DOI: $10.14260 /$ jemds/2014/2246

ABSTRACT: Stunted growth of an individual occurs in many systemic conditions and the main cause is due to defective cartilage growth in the long bones particularly in the lower extremities. In achondroplasia and Ellis Van Creveld syndrome the endochondral ossification of long bones are affected but in Ellis Van Creveld syndrome, the stunted growth is associated with ectodermal dysplasia, polydactyly and cardiac diseases. The common feature for both achondroplasia and Ellis Van Creveld syndrome is the individual's trunk is normal but the lower extremities are short. Though there is a cartilage dysfunction in these two cases, different clinical manifestation occurs in the body and these things are recorded from two case reports of Achondroplasia and Ellis Van Creveld syndrome and submitted the clinical differences with explanation and discussion.

KEYWORDS: Achondroplasia, Ellis Van Creveld (EVC) syndrome, dwarfism, scoliosis, trident hand, polydactyly.

INTRODUCTION: Achondroplasia is a condition in which there is a disturbance of cartilage function and it is caused by a change in the DNA for fibroblast growth factor receptor 3 (FGFR 3)1,2 which causes an abnormality of cartilage formation. In Achondroplasia the growth of long bones are affected due to the defective cartilage growth in the epiphyseal end causing the main feature of rhizomelic disproportionate short stature. This skeletal dysplasia occurs 1 in $30000^{3}$.

EVC syndrome or Chondroectodermal dysplasia is a condition in which cartilage growth is affected causing stunted growth. This condition is associated with ectodermal dysplasia, polydactyly and cardiac diseases. This is an autosomal recessive disorder with mutation of EVC - 1, EVC - 2 genes located in chromosome $4 \mathrm{p} 16^{4,5}$.

Though, the two conditions are mainly associated with cartilage dysfunction their clinical characteristics vary and the different clinical features of these two cases are described and their significance is discussed in this article.

\section{CASE REPORTS:}

ACHONDROPLASIA: A male patient 45 years of age with short stature reported for the complaint of stunted growth and difficulty of using his left hand. The patient had stunted growth. His height was $124 \mathrm{~cm}$ and body weight was $37 \mathrm{~kg}$ he was not anxious and tensed. His vital signs were normal with no cardiac pulmonary and kidney disease. On clinical examination, the vault of the skull appears large 4and base of the skull is short as brachycephaly with frontal bossing. Face appeared as flat with depressed bridge of the nose. Hypoplasia of middle third of the face with maxillary retrusion, teeth occludes edge to edge were seen. Upper limbs are short and bent in left side with free movements of elbow joint. When the patient stands his fingers upper extremities touched the upper part of the iliac bone. Mild enlargement of fingers were seen in the hand and in left hand there is a space between middle finger and ring finger - the trident hand. ${ }^{6}$ The trunk appears to be normal in size for his age 
and the length of the trunk is more than the length of the lower extremity. In the trunk there is curvature of thoracolumbar spine giving the appearance of shifting the chest towards the left side with the midline of face and the trunk are altered - the classical scoliosis. The femur, tibia and fibula were very short due to failure of cartilage growth. Muscles attached to the long bones are thick and bulbous. The patient was having protruding abdomen, prominent buttocks and lumbar lordosis. The clinical findings are suggestive of Achondroplasia.

ELLIS VAN CREVELD SYNDROME: A boy of 14 years old presented with complaint of stunted growth on clinical examination the head was normal in size. Hair on the skull, eyebrow and eyelashes were scanty with mild depression of the nasal bridge. Face was normal. Fusion of labial mucosa in the upper lip with gingiva over the alveolus of the incisor region obliterating the labial sulcus with thickening in the labial frenum area was seen7. Partial anodontia with malformed teeth were seen. Fingers of both hands are bulbous and affected with polydactyly. In each hand there are seven fingers of which two fingers are fused and appear as syndactyly. Nails of the fingers are dystrophic. His trunk appears to be normal in length with long narrow chest. The height of the trunk is more than the height of lower extremities. Knock knee with genu valgum was present. As per the cardiologist report patient had mitral and tricuspid valvular defects associated with atrial and ventricular septal defects. Murmurs were heard but not much sound.3, 6 As the patient had developed disturbances in ectodermal and chondral structures with cardiac manifestations and polydactyly the condition was diagnosed as EVC syndrome8.

ANALYSIS OF THE CASES: The skull appears large in the vault and short in the base in Achondroplasia but not in Ellis Van Crevald syndrome. Depression of the bridge of the nose is prominent in Achondroplasia but not prominent in EVC syndrome. This is due to the failure of cartilage growth in the base of the skull which also responsible for the retrusion of the maxilla. No skull changes are seen in the EVC syndrome. This shows that the cartilage disturbances in the base of the skull were not found.

The length of the trunk with narrow chest, the stunted growth of upper and lower extremities, knock knee with genu valgum are quite common findings in Achondroplasia ${ }^{9}$ and EVC syndrome. This shows the defective cartilage growths in long bones are similar in both the conditions.

Hand and finger changes are seen as trident fingers ${ }^{6}$ in Achondroplasia but polydactyly and syndactyly in EVC syndrome. In Achondroplasia no cardiac changes but in EVC syndrome cardiac changes always occurs as valvular and septal defects ${ }^{3}$ with abnormal murmurs. In Achondroplasia ectodermal structures are normal but in EVC syndrome ectodermal dysplasia occurs as hair changes, nail changes malformed teeth and absence of teeth. The most important finding of fusion of labial mucosa with gingiva over the alveolus is found only in EVC syndrome and is not found in Achondroplasia or any other diseases. The reason for this fusion of labial mucosa with gingiva ${ }^{7}$ is not known though it has nothing to do with neither ectodermal changes nor mesodermal changes.

Muscular thickness 9 , Lumbar lordosis and severe scoliosis with prominent buttocks with protruding abdomen was seen in Achondroplasia and not seen in EVC syndrome. 
DISCUSSION: Disorder of cartilage causing stunted growth is common in both conditions but EVC syndrome cannot be called as a manifestation of Achondroplasia because there is no cartilage dysfunction in the base of the skull in EVC syndrome. Thus Achondroplasia is purely absence of cartilage function but in EVC syndrome there is cartilage dysplasia. Though it is a dysplasia of cartilage it satisfies the total absence of growth in extremities as we find in Achondroplasia. Short leg may be a cause for postural scoliosis in spine in achondroplasia. Short leg in Ellis Van Creveld syndrome is not producing scoliosis, the reason is not known. Mild hair changes, partial anadontia and dystrophy of nail are only the features of ectodermal dysplasia in EVC syndrome ${ }^{10}$ and changes in sweat glands and sebaceous glands are not found. This shows that ectodermal dysplasia is also a partial one in EVC syndrome. Literature shows that all cases of EVC syndrome show cardiac manifestations, polydactyly and syndactyly which are not at all present in Achondroplasia and Van Creveld themselves have discussed that there are cases with Achondroplasia which is associated with kidney disease but not heart disease ${ }^{10}$. But the only condition where the tetrad findings of cartilage dysplasia, ectodermal dysplasia, polydactyly and cardiac condions ${ }^{8}$ are present is EVC syndrome. The mortality is poor in EVC syndrome as many patients die in younger age due to cardiac changes but not in Achondroplasia.

CONCLUSION: It is concluded that though cartilage is affected and produce disorders in endochondral ossification causing stunted growth, it may be associated with other diseases also. Hence diagnosis of dysfunction of cartilage with other diseases has to be studied thoroughly for correct diagnosis of chondrodystrophies.

\section{BIBLIOGRAPHY:}

1. Afnan $\mathrm{Al}$, Saleem, Asma $\mathrm{Al}$, Jobair. Achondroplasia. Craniofacial manifestations and considerations in dental management. The Saudi Dental Journal. 2010; 22: 195 - 9.

2. Horton WA, Degnin CR. FGF's in Endochondral Skeletal Development. Trends Endocrinol Metab. 2009; 20:341 - 8 .

3. Trinath Mishra, Satya N. Routray, Biswajit Das. Late survival in Ellis - Van Creveld Syndrome A case report. Indian Heart Journal. 2012; 64: 408 -11.

4. Horton WA, Rotter JI, Rimoin DL, Scott C, Hall JG. Standard Growth Curve for Achondroplasia. J Pediatr. 1978; 93:435 - 8.

5. Genevieve Baujat, Martine Le Merrer. Ellis Van Creveld syndrome. Orphanet Journal of Rare diseases. 2007; 2:1 - 5 .

6. RM Shenoy, Essentials of Orthopedics. First edition. 2010.

7. Caffery J. Chondroectodermal dysplasia - Report of three cases. American Journal of Roentgenology. 1952; 68: 875 - 86.

8. Digilio M Marino et al. Cardiac malformation in patients with orofacial skeletal syndrome. Am J Med Genetics. 1999; 84:350-56.

9. Genevieve Baujat, Laurence Legeai Mallet, George Finidois, Valerie Cormier Daire. Achondroplasia. Best Practice \& Research Clinical Rheumatology. 2008;22(1): 3 -18.

10. Richard WB. Ellis S Van Crevald. A syndrome characterized by ectodermal dysplasia, polydactyly, chondro dysplasia and congenital morbuscordis - report of three cases. Arch Dis Child;1940:15:65 


\section{CASE REPORT}

\section{ELLIS VAN CREVELD SYNDROME:}

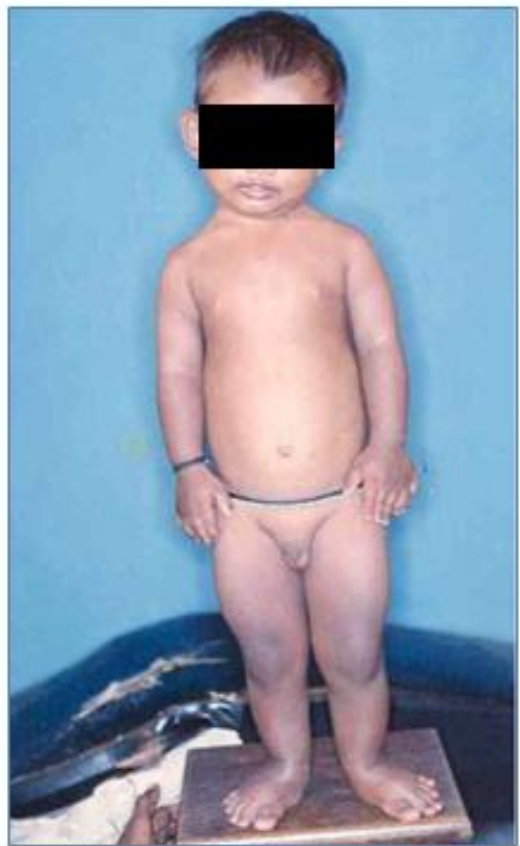

STUNTED GROWTH

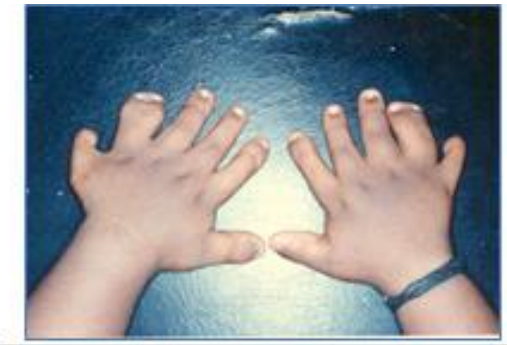

\section{POLYDACTYLY AND SYNDACTYLY}

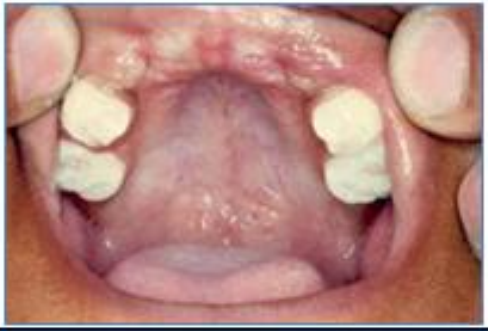

FUSION OF LIP AND GINGI'VAOBLITERATING THE SULCUS IN THE LABIAL FRENUM AREA

\section{ACHONDROPLASIA:}
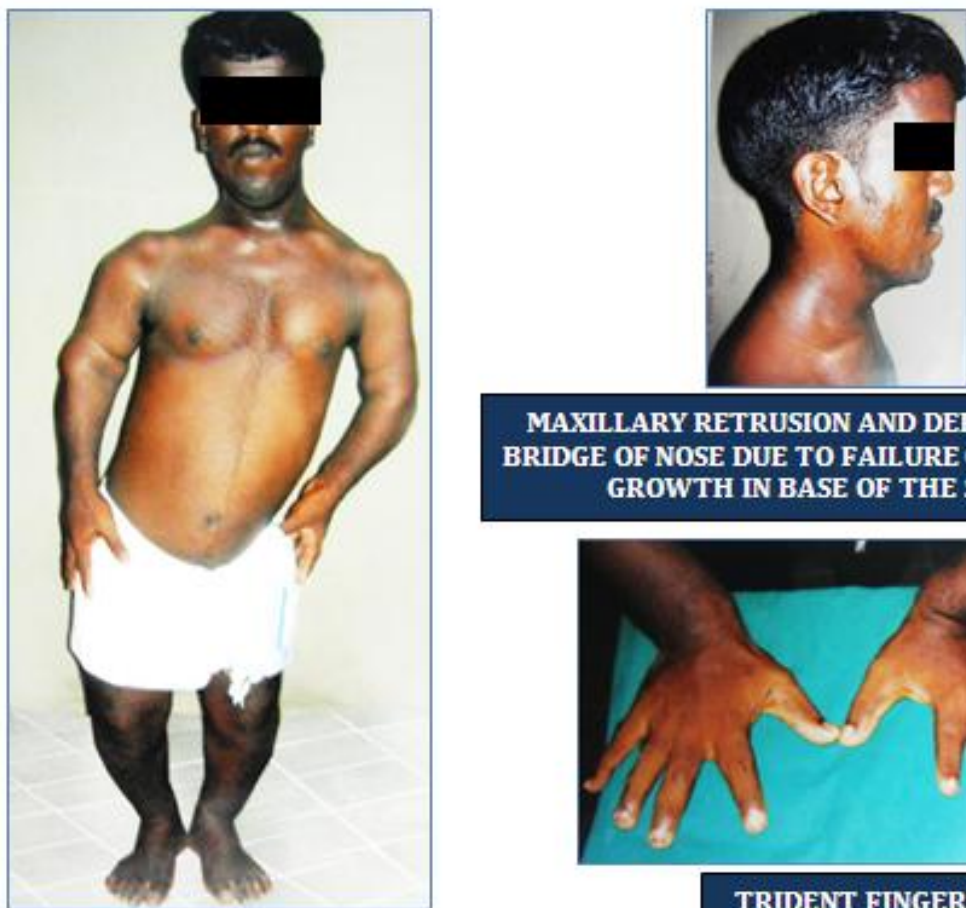

MAXILLARY RETRUSION AND DEPRESSION OF BRIDGE OF NOSE DUE TO FAILURE OF CARTILAGE GROWTH IN BASE OF THE SKULL

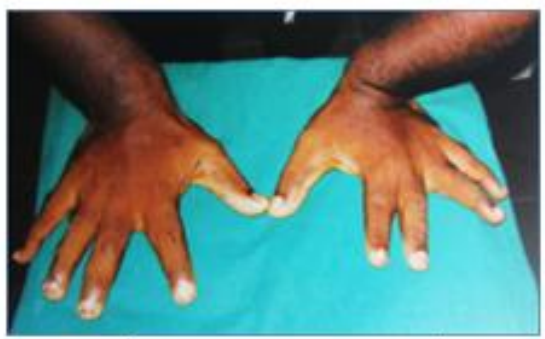

TRIDENT FINGERS

STUNTED GROWTH WITH THORACOLUMBAR CURVATURE - SCOLIOSIS 


\section{CASE REPORT}

\section{AUTHORS:}

1. G. Ramkumar

2. P. Shanmugasundaram

3. V. L. Narayanan

\section{PARTICULARS OF CONTRIBUTORS:}

1. Associate Professor, Department of Orthopaedics, Saveetha Medical College, Chennai.

2. Associate Professor, Department of Orthopaedics, Saveetha Medical College, Chennai.

3. Assistant Professor, Department of Orthopaedics, Saveetha Medical College, Chennai.

\section{NAME ADDRESS EMAIL ID OF THE} CORRESPONDING AUTHOR:

Dr. G. RamKumar, AH 94, $4^{\text {th }}$ Street, Shanthi Colony, Annanagar, Chennai - 40.

E-mail: kg.ramkumar@yahoo.com

Date of Submission: 14/02/2014.

Date of Peer Review: 15/02/2014.

Date of Acceptance: 20/02/2014.

Date of Publishing: 20/03/2014. 